\title{
Subject Characteristics Yes No Indicator
}

National Cancer Institute

\section{Source}

National Cancer Institute. Subject Characteristics Yes No Indicator. NCI Thesaurus. Code C87998.

An indication of whether or not a subject characteristics assessment has taken place. 